\title{
International Comparisons of Economic Burden of End- Stage Renal Disease to the National Healthcare Systems
}

\author{
Ismail $H^{a}$, Abdul Manaf $M R^{b}$, Abdul Gafor $A H^{c}$, Mohamad Zaher $Z M^{d}$, Nur Ibrahim Al $l^{e}$ \\ ${ }^{a}$ Department of Community Health, Faculty of Medicine, Universiti Kebangsaan Malaysia \\ ${ }^{b}$ Department of Community Health, Faculty of Medicine, Universiti Kebangsaan Malaysia \\ 'Department of Medicine (Nephrology), Faculty of Medicine, Universiti Kebangsaan Malaysia \\ ${ }^{d}$ KPJ Ampang Puteri Specialist Hospital \\ e Institute of Mathematical Sciences, Faculty of Science, University of Malaya
}

\section{ABSTRACT}

The global prevalence of chronic kidney disease (CKD) is between 11 to $13 \%$. Renal replacement therapies (RRT) - which include dialysis and renal transplantation - consume a significant portion of a country's health resources even though only $0.1 \%$ of all CKD patients are at stage 5, also known as end-stage renal disease (ESRD). The aim of this review was to compare the magnitude of the economic burden of ESRD on national healthcare systems of selected countries with high prevalence of ESRD including Malaysia. The quantity of interest in this review were total ESRD expenditures and its proportions to the national health systems' expenditure. It was identified that total ESRD expenditure contributes between $0.91 \%$ to $7.1 \%$ of national health system expenditure in countries selected for this review. In Malaysia, the public sector - through its various agencies at the federal and state levels, accounted for almost $70 \%$ of dialysis funding; the remaining $30 \%$ came from the private sector and out-of-pocket payments. The ESRD expenditures in Malaysia constitutes $4.2 \%$ of total health expenditure by the public sector, relatively high compared to other countries. This review will summarise findings of the currently available economic evaluations of RRT in Malaysia. Based on available evidence, estimated weighted cost of treating ESRD patient in Malaysia is MYR39,346 per patient per year (USD26,648, PPP 2016).

KEYWORDS: chronic kidney disease, end stage renal disease, dialysis, renal transplantation, national health expenditure

\section{INTRODUCTION}

Chronic kidney disease (CKD) is defined as an abnormal renal structure or function which lasts for more than three months with implications on health ${ }^{1}$. CKD is classified into stages 1-5 with reference to the glomerular filtration rate (GFR) - a clinical indicator of kidney function. An individual who has evidence of renal damage but normal GFR will be classified as stage 1. As the GFR or kidney function deteriorates, the individual will

Corresponding Author:

Dr. Hirman Ismail

Department of Community Health,

Faculty of Medicine,

Universiti Kebangsaan Malaysia,

Jalan Yaacob Latif, Bandar Tun Razak,

56000 Cheras, Kuala Lumpur Malaysia.

Tel No: +60172001377

Email: drhirman@outlook.com progress to the more advanced stages of CKD. Stage 5 is also known as end-stage renal disease (ESRD), for which the mainstay of treatment is renal replacement therapy (RRT) - dialysis and renal transplantation.

The global prevalence of CKD is around 11 to $13.4 \%$, and the majority of patients are at stage 3 . The global prevalence of CKD by stages is as follows; stage 1 (3.5\%); stage $2(3.9 \%)$; stage $3(7.6 \%)$; stage 4 $(0.4 \%)$; and stage $5(0.1 \%)^{2}$. In Malaysia, $9.1 \%$ of the population have CKD with the majority are at stage $1^{3}$. The prevalence of CKD in Malaysia by stages is as follows; stage $1(4.16 \%)$; stage $2(2.0 \%)$; stage 3 (2.26\%); stage $4(0.24 \%)$; stage $5(0.36 \%){ }^{3}$

RRTs are considered expensive and resource intensive. Even though stage 5 CKD patients 
constitute a relatively small proportion of the entire CKD population ( $0.1 \%$ globally, $0.36 \%$ in Malaysia), it has significant impact on the national healthcare expenditure. While full economic comparisons of the cost-effectiveness, cost-utilities, and costbenefits of the different modalities of RRTs are widely available in the literature, studies on the microeconomic consequences of stage 5 CKD to the national healthcare system are limited. This review was intended to summarise published data on total ESRD expenditure among countries with high prevalence of ESRD, as well as to understand the magnitude of the economic burden of ESRD to the national healthcare systems.

\section{METHODOLOGY}

Literature searches were conducted in major databases such as PubMed and Medline. Focused internet searches were also performed to obtain published articles on the economic burden of stage 5 CKD or ESRD to the national health systems of selected countries. The countries were selected from a list of countries with the highest prevalence of ESRD based on the US Renal Data System (USRDS) international comparison. ${ }^{4}$ Treatment options that were included in this review comprised of conservative management and/ or RRTs (i.e. dialysis and renal transplantation). The quantities of interest here were 1) national ESRD expenditures and 2) percentages of the same with respect to the countries' respective total healthcare expenditures. ESRD expenditure is referred to as the total spending of a country - either by national health services or social health insurances - on all types of RRTs or as cited by the literatures. Only researches that reported at least one of the abovementioned quantities were selected for reviewing. Studies which compared the economics of various RRT modalities (i.e. cost-effectiveness, -utilities, or -benefits) were not included. The works that were written in languages other than English were also excluded. All monetary values were expressed in US Dollars (USD), which were adjusted according to the corresponding country's purchasing power parity (PPP) conversion factor as published in the World Bank Open Data website (https:// data.worldbank.org/).

\section{RESULTS AND DISCUSSION}

A total of 20 countries - Australia, Belgium, Canada,
Denmark, France, Germany, Italy, Japan, Korea, Mexico, New Zealand, Norway, Portugal, Singapore, Spain, Sweden, Taiwan, Thailand, United Kingdom (UK), and US were selected for this review. However, estimates on national ESRD expenditures were only available in literatures involving thirteen countries, as outlined in Table 1. An article on economic burden of ESRD in Mexico ${ }^{5}$ was written in Spanish and therefore was not included in the review. US and Taiwan had the highest proportions of ESRD expenditure with respect to their national health insurance systems $(7.1 \%$ and $7.0 \%$ respectively). ${ }^{6,7}$ Based on the 2017 US Renal Data System Report, Taiwan, Japan, and US were the three countries with the highest prevalence rate of ESRD - 3,317 per million population (pmp), 2,529 pmp, and 2,138 pmp respectively. ${ }^{4}$ Therefore, the high proportions of ESRD expenditure documented by US and Taiwan were justified. On the other hand, Japan reported that 3.8\% (USD 13.85 billion per year) of its total medical spendings were allocated for ESRD $^{8}$. It is important to note that the proportions of expenditure were reported with reference to the national health insurance systems and not the countries' total healthcare expenditure. Apart from the high prevalence of the disease, a few other factors could explain the high ESRD expenditures in these countries. Hirth (2007) suggested that the relatively higher cost of ESRD management in the US was attributable to the universal health coverage and input cost inflations (including the salaries of the health personnel). ${ }^{9}$ It was estimated that the cost of treating an ESRD patient in 2002 was USD 55,000 per patient per year in the US Medicare system and USD 72,000 per patient per year as per the employee groups' health plans; these values were higher as compared to that in Japan - USD 41,628 per patient per year (PPP, 2003). ${ }^{10}$

In the US, Medicare accounted for a large share (over three-quarters) of the US's ESRD expenditure. ${ }^{11}$ Even though ESRD is present in only less than $1 \%$ of total Medicare population, it takes up more than $7 \%$ of Medicare's total expenditure. Nevertheless, the percentage has remained stable since 2004. In keeping with the increase in the overall expenditure of Medicare, the total spending on ESRD patients has increased by $2.4 \%$ between 2014 and 2015 . However, within the same period, the overall expenditure on haemodialysis did not grow, unlike expenditure on peritoneal dialysis and renal transplantation, which 
were raised by $3.0 \%$ and $4.7 \%$ respectively. ${ }^{12}$ In 2011 , the introduction of a "bundle system" as new reimbursement scheme that provided financial incentives for home-based dialysis could have explained the increase in the expenditure on peritoneal dialysis ${ }^{13,14}$, but not on haemodialysis. The prospective payment system, or "bundle system", was a cost-containment strategy introduced by the US Centre for Medicare and Medicaid. Its implementation followed the enforcements of the Medicare Improvement for Patients and Providers Act in 2008 by the US Congress. The bundle system would benefit the dialysis centres and nephrologists by USD 8,000 and USD 1,300 per case respectively if home dialysis was initiated rather than in-centre haemodialysis. ${ }^{13}$ Such incentives have influenced the trends of RRT distributions in US. ${ }^{15}$ It was also identified that subsequent to the implementation of the "bundle system" in 2011, the usage of more expensive drug alternatives like erythropoietin and vitamin D analogues have significantly reduced while the utilisation of home-based dialysis - peritoneal dialysis and home haemodialysis - increased. ${ }^{15}$ Hirth (2007) also has suggested that the high transplantation rate had an influence on the costcontainment strategy for the treatment of ESRD in US. ${ }^{9}$ The cost-effectiveness of renal transplantation over dialysis is well-established. ${ }^{16}$ Economic modelling studies have also shown that the total expenditure on ESRD can be reduced if the government introduces measures to increase the rates of transplantation instead of haemodialysis and peritoneal dialysis. ${ }^{17,18}$ The rate of kidney transplantation in the US was the third highest in the world (51 per million population) after Mexico (71 per million population) and Spain (62 per million population). ${ }^{4}$

Data on ESRD expenditure in Taiwan and Japan were not as well-documented as that of the US. For example, the methodology of estimating ESRD expenditure in Japan as reported by Fukuhara et al. (2007), was not thoroughly elaborated. There was no specific comprehensive database for ESRD in Japan, so secondary data analyses were used to obtained the estimate from other sources like the Japanese Society for Dialysis Therapy and data from the Ministry of Health, Labour and Welfare (MHLW). Similar to the "bundle system" of US, Japan employs a mixture of prospective payment $(79 \%)$ and fee-for-service $(21 \%)$ systems in its reimbursement strategies. There is no incentive for peritoneal dialysis in Japan since it is suggested that the incidence of peritoneal dialysis is unlikely to improve. ${ }^{19}$ Likewise, in Taiwan, the low usage of peritoneal dialysis is in view of the higher haemodialysis reimbursement rate by the national health insurance policy. Therefore, haemodialysis is usually the first-line treatment in Taiwan. ${ }^{20}$

The proportion of ESRD expenditure with respect to the overall healthcare spending by Thailand was $3.4 \%$ (USD315 million) $^{21}$ followed by Italy $1.8 \%{ }^{22}$, Spain $1.5 \%{ }^{23}$ and Australia $1.7 \%$, or USD 658.4 million on CKD of which $85 \%$ was accounted for by ESRD expenditure $(1.4 \%$ of the total healthcare expenditure, or USD 556.8 million) ${ }^{24}$. As for the UK, USD 2.04 billion was spent on CKD management, of which USD 1.42 billion was for ESRD. The CKD expenditure contributed to $1.3 \%$ of total NHS expenditure ${ }^{25}$. Meanwhile, both Canada and France spent $1.3 \%$ of their total health expenditures on ESRD. ${ }^{26-28}$ New Zealand spent $0.91 \%$ of its total healthcare expenditure on ESRD ${ }^{29}$ - the lowest reported expenditure in this review. Singapore spent USD 89.9 million on dialysis in $2000^{30}$, but its total expenditure on renal transplantation was not available.

\section{Economic burden of ESRD to the Malaysian healthcare system}

The Malaysia Dialysis and Transplantation registry collects annual data from all dialysis centres in Malaysia including on source of funding of dialysis treatment. It was identified that public sector has remained the main contributor of dialysis funding in Malaysia (Figure 1). In 2007, 55.5\% of all dialysis expenditure were accounted for by the public sector, but out-of-pocket payments remained high at 25\%. From 2006 to 2016, the total contribution by the public sector has increased to $67.1 \%$, while outof-pocket payments reduced to $14.9 \%$. Meanwhile, the private sector contributed only $15.7 \%$ to the funding of dialysis treatment in 2016. ${ }^{31}$

In a study published in 2019 , it was found that the ESRD expenditure by the public sector in Malaysia constituted $4.2 \%$ of total health expenditure (public sector). This makes ESRD expenditure in Malaysia the third highest in this review after the US and Taiwan. It was identified that the ESRD expenditure has increased by $94 \%$ within a period of seven years, 
from USD405 million in 2010 to USD785 million in 2016. ESRD expenditure grew faster at $11.8 \%$ per annum compared to the total health expenditure (5.5\% per annum $)^{32}$. This makes Malaysia a country with the third highest ESRD expenditure in this review, relative to the expenditure of national healthcare system (Table 1 ).

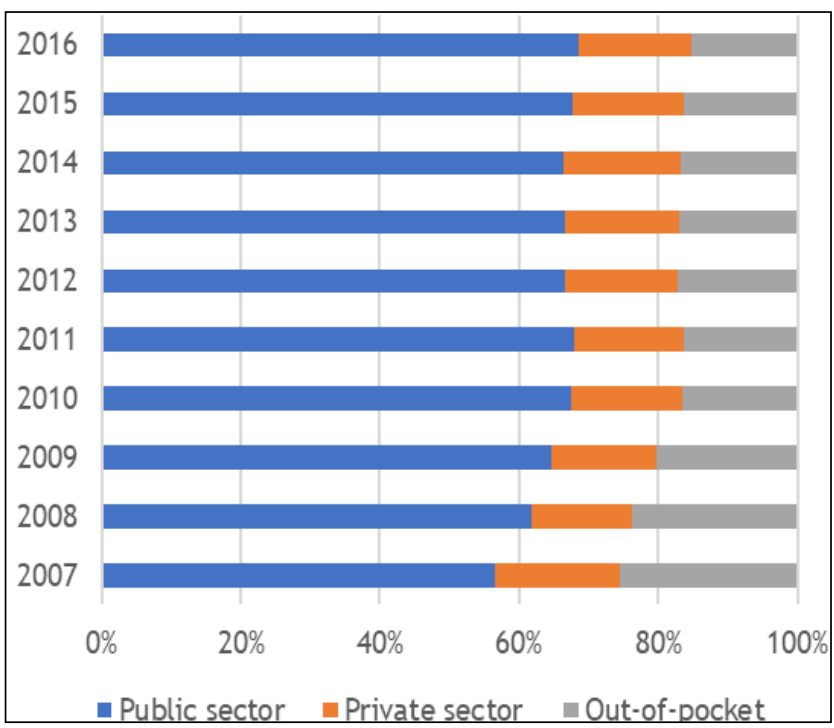

Figure 1: Funding distribution of dialysis in Malaysia, by year

Source: Malaysian Dialysis and Transplantation Registry

The public sector's dialysis expenditure does not only constitute that by the Ministry of Health, but by many other governmental agencies at the federal and state levels like the Ministry of Education, Ministry of Defence, Department of Public Services, Social Security Fund (SOCSO), and the state government-owned zakat (tithes) organisations. There are 14 zakat (a form of mandatory contribution of a part of the Muslims' wealth to be given to the poor or other beneficiaries in Malaysia), all of which are managed by the State Islamic Religious Councils (SIRCs) that coordinate the collection and distribution of zakat. There is no centralised mechanism to keep track of the annual spendings of these government agencies on dialysis and renal transplantations. The differences in the accounting systems of these agencies may explain the difficulty of documenting the yearly expenditure on RRTs. Furthermore, the state-owned zakat organisations' accounting systems are not linked to the ones managed by the federal government.

Ismail $\mathrm{H}$ et al (2019) complements the work of Bavanandan el al (2016). Bavanandan et al. (2016) conducted a budget impact analysis to compare the invariable distributions of the total cost of haemodialysis and peritoneal dialysis over five years (2014 - 2018). The analysis was done on the basis that the government - through its agencies like the Ministry of Health, Ministry of Defence, Department of Public Services, and SOCSO - was the main funder of dialysis in Malaysia. The cumulative burden of dialysis on the government over the five years was estimated to be MYR 3,848,000,000 (USD 2,674,079,211; PPP 2014), which translated into an average of MYR 769,600,000 (USD 534,815,844; PPP 2014) per year. The outcomes of modelling analyses revealed that an increase in the usage of peritoneal dialysis could help the government save between MYR 7.98 million (USD 5.56 million; PPP 2014) and MYR 23.93 million (USD 16.66 million; PPP 2014) yearly. Conversely, a decrease in utilisation of peritoneal dialysis could increase the overall spending by MYR 3.19 million (USD 2.22 million; PPP 2014) annually. The estimated cost of dialysis was based on modelling rather than actual historical expenditure on dialysis. Hence, factoring-in of the contributions of all 14 zakat institutions nationwide may result in a significantly higher estimate of the economic burden of dialysis on the public sector in Malaysia.

Cost for hospitalisation and indirect medical services like transportation - which has not been accounted for in this analysis, may again increase the estimate. Furthermore, the evaluation also excluded renal transplantation, which would otherwise have provided better insight into the total economic burden of ESRD on Malaysia's healthcare system in a manner similar to those of other countries as mentioned in the earlier section of this review.

Compared to Bavanandan et al (2010), Ismail $\mathrm{H}$ et al (2019) has included renal transplantation as part of ESRD expenditure. On top of that Ismail $\mathrm{H}$ et al (2019) conducted a thorough primary data collection from all public sector agencies involved in financing RRT including all zakat organisations.

Comparisons on the cost-effectiveness of haemodialysis and peritoneal dialysis in Malaysia were conducted by Hooi et al. (2005). The study was carried out at 44 and 11 hospital centres nationwide respectively. It was identified that the extent of prolongation of survival was lower in the peritoneal dialysis (5.21 years) than in haemodialysis (10.96 years). 
Table 1: National expenditure on end stage kidney disease or chronic kidney disease stage 5 of selected countries

\begin{tabular}{|c|c|c|c|c|}
\hline Country & $\begin{array}{l}\text { Prevalence of } \\
\text { ESRD (pmp) }\end{array}$ & $\begin{array}{l}\text { Total expenditure } \\
\text { on ESRD per year } \\
\text { (USD PPP) }\end{array}$ & $\begin{array}{c}\text { Percentage against } \\
\text { total health expendi- } \\
\text { ture (\%) }\end{array}$ & $\begin{array}{c}\text { Source, corresponding } \\
\text { year }\end{array}$ \\
\hline US & 2,128 & USD 34 billion & $\begin{array}{l}7.1 \% \text { of total Medicare } \\
\text { expenditure on ESRD }\end{array}$ & USRDS (2017), 2016 \\
\hline Taiwan & 2,470 & NA & $\begin{array}{l}7.0 \% \text { of total national } \\
\text { health insurance ex- } \\
\text { penditure on ESRD }\end{array}$ & Yang \& Hwang (2008), 2008 \\
\hline Malaysia & 1,352 & USD706 million & $\begin{array}{l}4.2 \% \text { of total heath } \\
\text { expenditure (public } \\
\text { sector) }\end{array}$ & Ismail H et al (2019), 2016 \\
\hline Japan & 1,850 & USD 13.85 billion & $\begin{array}{l}3.8 \% \text { of the total medi- } \\
\text { cal cost on ESRD }\end{array}$ & $\begin{array}{l}\text { Nawata \& Kimura (2017), } \\
2010\end{array}$ \\
\hline Thailand & 1,515 & USD315 million & $\begin{array}{l}3.4 \% \text { of total budget of } \\
\text { Universal Health Cov- } \\
\text { erage Scheme }\end{array}$ & Tantivess S (2013), 2012 \\
\hline Italy & 928 & NA & $\begin{array}{l}1.8 \% \text { of the total } \\
\text { health expenditure on } \\
\text { ESRD }\end{array}$ & $\begin{array}{l}\text { Pontoriero et al (2007), } \\
2001\end{array}$ \\
\hline Spain & 925 & NA & $\begin{array}{l}1.5 \% \text { of total health } \\
\text { expenditure on ESRD }\end{array}$ & Luno (2007), 2005 \\
\hline Australia & 913 & $\begin{array}{l}\text { USD } 658.4 \text { million on } \\
\text { CKD (USD556.8 mil- } \\
\text { lion on ESRD) }\end{array}$ & $\begin{array}{l}1.7 \% \text { of total health } \\
\text { expenditure were } \\
\text { spent on CKD (1.4\% } \\
\text { were spent on ESRD) }\end{array}$ & $\begin{array}{l}\text { Tucker et al. (2014), } 2012 \\
\text { Australian Institute of } \\
\text { Health and Welfare (2009), } \\
2004\end{array}$ \\
\hline UK & 794 & $\begin{array}{l}\text { USD } 2.04 \text { billion on } \\
\text { CKD (USD1.42 billion } \\
\text { on ESRD) }\end{array}$ & $\begin{array}{l}1.3 \% \text { of total NHS ex- } \\
\text { penditure were spent } \\
\text { on CKD including ESRD }\end{array}$ & $\begin{array}{l}\text { Marion Kerr et al (2012), } \\
2009\end{array}$ \\
\hline Canada & 1,066 & USD 1.07 billion & $\begin{array}{l}1.3 \% \text { of total health } \\
\text { expenditure on ESRD }\end{array}$ & Zelmer(2007), 2007 \\
\hline France & 823 & $\begin{array}{l}\text { USD } 2.29 \text { billion (on } \\
\text { dialysis) }\end{array}$ & $\begin{array}{l}1.3 \% \text { of total health } \\
\text { expenditure on ESRD }\end{array}$ & $\begin{array}{l}\text { Durand-Zaleski et al. } \\
\text { (2007), } 2005 \\
\text { Benain et al. (2007), } 2007\end{array}$ \\
\hline New Zealand & 714 & NA & $\begin{array}{l}0.91 \% \text { of the total } \\
\text { health expenditure on } \\
\text { ESRD }\end{array}$ & $\begin{array}{l}\text { Ashton \& Marshall (2007), } \\
2003\end{array}$ \\
\hline Singapore & 848 & $\begin{array}{c}\text { USD } 89.9 \text { million (on } \\
\text { dialysis) }\end{array}$ & NA & Tan et al. (2005), 2000 \\
\hline
\end{tabular}

Abbreviation: pmp, per million population; CKD, chronic kidney disease; PPP, purchasing power parity; ESRF, end stage renal failure; $N A$, not available

Notes: all monetary values have been converted to the corresponding year purchasing power parity (PPP) conversion factor published on the World Bank Open Data website

Continuous ambulatory peritoneal dialysis (CAPD) was identified to be marginally cost-effective than haemodialysis (HD) [CAPD: MYR 31,634.93 (USD 24,686; PPP 2005) per year of life saved and HD: MYR 33,642 (USD 26.262; PPP 2005) per life year saved]. ${ }^{33}$ Cost of consumables accounted for a larger portion of the overall expenditure on CAPD as compared to HD which was dominated by cost of building, salary, overhead, and equipment cost. Owing to the marginal difference in the incremental cost-effectiveness ratio between both modalities, it has been suggested that CAPD and HD can be promoted equally in Malaysia. The higher overall cost of HD may be offset by the better outcome of
HD. The lower survival rate of CAPD was attributable to its usage by older patients who lived far from HD centres, vascular access issues and cardiovascular problems. The main advantage of CAPD is its low capital and low fixed cost, even though the cost of its consumables is higher. An updated cost analysis on HD and PD was done in 2016 revealed that the cost of HD and PD were MYR39,790 (USD27,962; PPP 2016) and MYR37,576 (USD26,406; PPP 2016) per patient per year respectively. ${ }^{34}$ Consumer price index (CPI) 2016 adjusted cost of HD and PD by Hooi et al (2005) would be MYR42,633 and MYR40,090 respectively, meaning, the cost of $H D$ and $P D$ have dropped when compared to findings by Surendra et 
al (2018). Annual cost of drugs was found to be lower than the earlier study due to lower price of erythropoietin and the use of generic drugs. ${ }^{34}$ The cost consumables were found to be higher in PD in 2018 study compared to the previous study due to the use of twin-bag system in the current practice. 34

Bavanandan et al. (2015) also performed a costutility analysis of renal transplantations (RT) for both paediatric and adult patients in Malaysia. This was a partial economic evaluation as the study described cost-utility of renal transplantation without comparing it with other RRT modalities. As with Hooi et al. (2005), the study employed a microcosting approach which involved 118 adult and 88 paediatric patients. As mentioned, the analysis was conducted from the perspective of the Ministry of Health. The cost of living and deceased RTs in adults was USD 8,609 (MYR 29,482) and USD 13,209 (MYR 45,234) per life year saved respectively. When adjusted for quality of life, the values were USD 8,826 (MYR 30,224) and USD 13,592 (MYR 46,546) respectively. As for the paediatric group, the corresponding values were USD 10,485 (MYR 35,905) and USD 14,985 (MYR 51,317) per life year saved. In terms of total lifetime cost, the values in adults were USD 119,702 (MYR 409,921) and USD 147,152 (MYR 503,922) respectively, while those in children were USD 154,841 (MYR 530,252) and USD 159,313 (MYR 545,566) respectively. ${ }^{35}$ The disadvantage of the study was that it did not properly compare RT with alternatives like HD or PD through costeffectiveness or -utility analyses. However, it was mentioned that the calculated average cost of transplantation compared favourably with the cost of HD and PD [USD 11, 843 (MYR 40,557) and USD 11,137 (MYR 38,138)] respectively when the reported cost by Hooi et al (2005) were adjusted to 2009 values.

With reference to the information above, the average cost of ESRD in Malaysia can be estimated by assigning weightages to the annual cost of each RRT modality (haemodialysis, peritoneal dialysis, live renal transplantation, deceased renal transplantation) per patient. Weightages are assigned based on proportion of patients receiving treatment for each modality, determined from the prevalence data in the 2017 Malaysian Dialysis and Transplantation Registry. ${ }^{31}$ This method of estimation is consistent with estimation done by Luno (2007), Fukuhara et al. (2007), Durand-Zaleski et al. (2007), as well as Kleophas and Reichel (2007). ${ }^{10,23,27,36}$ The reported annual cost of each modality per patient was adjusted to 2016 values with reference to the corresponding year's consumer price index (CPI). The final estimations were then converted to US dollar as per the World Bank's purchasing power parity (PPP) conversion factor. ${ }^{37,38}$ Table 2 outlines the estimates of the cost of ESRD in Malaysia.

For comparison, the yearly cost of ESRD per patient in other countries is as follows: US (USD 55,000), Germany (USD 46,905; PPP 2003), Canada (USD 45,095; PPP 2002), France (USD 45,327; PPP 2003), Japan (USD 41,681; PPP 2003), Sweden (USD 40,054; PPP 2003), Italy (USD 38,427; PPP 2001), Spain (USD 30,270; PPP 2003), and New Zealand (USD 23,372; PPP 2003).

\section{CONCLUSION}

ESRD expenditures accounted for $0.91 \%$ to $7.1 \%$ of the national health system expenditures of selected countries in this review. US, Taiwan, Malaysia and Japan had the highest ESRD expenditures to the expenditure of national health system - 7.1\% (of Medicare expenditure), $7.0 \%$ (of national health insurance expenditure), $4.2 \%$ (of total health expenditure by the public sector) and 3.8\% (of total medical expenditure) respectively. No benchmarks were available to determine to what extend the proportion of expenditure on a specific disease against the national healthcare expenditure can be considered high or otherwise. It was identified that there was lack of standardisation and details of reporting of ESRD expenditure, especially methodologies in these literatures.

Based on the available published data as summarised in this review, economic burden of ESRD to the Malaysian healthcare system can be considered substantial, comparable with countries with the highest prevalence of ESRD in the world such as US, Taiwan and Japan. This can be seen from the significant proportion of the total health expenditure (public sector) allocated to support the provision of RRT services in the country. Drastic preventive measures are needed to curb the escalating burden of diseases. 


\begin{tabular}{lccccc}
\hline & & & & \multicolumn{2}{c}{ Weighted cost } \\
\cline { 4 - 6 } RRT modality & Weight & $\begin{array}{c}\text { Cost / patient / } \\
\text { year (MYR) }\end{array}$ & $\begin{array}{c}\text { Cost / patient / } \\
\text { year - adjusted to } \\
\text { CPI 2016 (MYR) }\end{array}$ & $\begin{array}{c}\text { Cost / patient / } \\
\text { year } \\
\text { (MYR) }\end{array}$ & $\begin{array}{c}\text { Cost / patient / } \\
\text { year } \\
\text { (USD PPP 2016) }\end{array}$ \\
\hline HD & 0.862 & 39,790 & - & 34,299 & 23,103 \\
PD & 0.095 & 37,576 & - & 3,570 & 2,509 \\
RT (living) & 0.034 & 29,482 & 34,544 & 1,174 & 824 \\
RT (deceased) & 0.010 & 45,234 & 53,001 & 530 & 372 \\
Total cost of ESRD / patient / year & & & 39,574 & 27,771
\end{tabular}

Abbreviation: CPI, consumer price index; PPP, purchasing power parity; HD, haemodialysis; PD, peritoneal dialysis; $R T$, renal transplantation; ESRD, end stage renal disease; MYR, Malaysian Ringgit; USD, US dollars

Notes: the cost of HD and PD need not be adjusted to CPI 2016 because the latest costs were obtained from a study done in 2016 by Surendra et al (2018)

Further research can be considered to make use of the available data to project future economic burden of ESRD in Malaysia to assist health planning and service development. Cost-effectiveness of promoting renal transplantation over dialysis in Malaysia shall be further assessed.

\section{ACKNOWLEDGEMENT}

This review was part of an ongoing research which was aimed to understand the microeconomic consequences of stage 5 CKD on the public sector in Malaysia. The said study was currently undertaken by the Department of Community Health, Faculty of Medicine, Universiti Kebangsaan Malaysia and at the time of writing, data collection has been completed to be analysed further. Special thanks to those agencies which have provided relevant input and data, namely the Ministry of Health, Department of Public Services, Ministry of Defence, SOCSO, and various zakat organisations.

\section{CONFLICT OF INTEREST}

The authors declare that they have no potential conflicts of interest with respect to the research, authorship, and/ or publication of this article.

\section{FUNDING}

The authors have disclosed the documents pertaining to the financial support for the research, authorship, and/ or publication of this article. The said assistance came from an unconditional research grant by the Malaysian Society of
Nephrology and the National Kidney Foundation. Both are not-for-profit non-governmental organisations.

\section{REFERENCE}

1. Levey AS, Eckardt K-U, Tsukamoto Y, et al. Definition and classification of chronic kidney disease: A position statement from Kidney Disease: Improving Global Outcomes (KDIGO). Kidney Int. 2005;67(6):2089-2100. doi:10.1111/j.1523-1755.2005.00365.x

2. Hill NR, Fatoba ST, Oke JL, et al. Global Prevalence of Chronic Kidney Disease - A Systematic Review and Meta-Analysis. PLoS One. 2016;11(7):e0158765. https:// doi.org/10.1371/journal.pone.0158765.

3. Hooi LS, Ong LM, Ahmad G, et al. A population-based study measuring the prevalence of chronic kidney disease among adults in West Malaysia. Kidney Int. 2013;84 (5):1034-1040. doi:10.1038/ki.2013.220

4. USRDS. Chapter 11: International Comparisons. USRDS. https:// www.usrds.org/2017/view/v2_11.aspx. Published 2017. Accessed July 23, 2018.

5. Cortés-Sanabria L, Álvarez-Santana G, Orozco -González CN, Soto-Molina H, MartínezRamírez HR, Cueto-Manzano AM. Economic impact of the chronic kidney disease: Perspective of the Instituto Mexicano del Seguro Social. Rev Med Inst Mex Seguro Soc. 2017;55(Suppl 2):S124-32. http:// www.ncbi.nlm.nih.gov/pubmed/29697222. Accessed June 11, 2019.

6. USRDS. 2016 Annual Data Report . Vol 
Volume 2: United States : United States Renal Data System ; 2016.

7. Yang W-C, Hwang S-J. Incidence, prevalence and mortality trends of dialysis end-stage renal disease in Taiwan from 1990 to 2001: the impact of national health insurance. Nephrol Dial Transplant. 2008;23(12):39773982. doi:10.1093/ndt/gfn406

8. Nawata K, Kimura M. Evaluation of Medical Costs of Kidney Diseases and Risk Factors in Japan. Vol 09.; 2017. doi:10.4236/ health.2017.913127

9. Hirth RA. The organization and financing of kidney dialysis and transplant care in the United States of America. Int J Health Care Finance Econ. 2007;7(4):301-318. doi:10.1007/s10754-007-9019-6

10. Fukuhara S, Yamazaki C, Hayashino $\mathrm{Y}$, et al. The organization and financing of end-stage renal disease treatment in Japan. Int $\mathrm{J}$ Health Care Finance Econ. 2007;7(2-3):217231. doi:10.1007/s10754-007-9017-8

11. US Renal Data System. Chapter 9 Healthcare Expenditures for Persons with ESRD. USRDS. https://www.usrds.org/2017/view/ v2_09.aspx. Published 2017. Accessed July 27, 2018.

12. USRDS. Chapter 9 Healthcare Expenditures for Persons with ESRD. USRDS. https:// www.usrds.org/2017/view/v2_09.aspx. Published 2017. Accessed July 25, 2018.

13. Golper TA. The Possible Impact of the US Prospective Payment System ("Bundle") on the Growth of Peritoneal Dialysis. Perit Dial Int. 2013;33(6):596-599. doi:10.3747/ pdi.2013.00212

14. Kaplan AA. Peritoneal Dialysis or Hemodialysis: Present and Future Trends in the United States. Contrib Nephrol. 2017;189:61-64. doi:10.1159/000450672

15. Hirth RA, Turenne MN, Wheeler JRC, et al. The Initial Impact of Medicare's New Prospective Payment System for Kidney Dialysis. Am J Kidney Dis. 2013;62(4):662669. doi:10.1053/j.ajkd.2013.03.044

16. HOWARD K, SALKELD G, WHITE S, et al. The cost-effectiveness of increasing kidney transplantation and home-based dialysis. Nephrology. 2009;14(1):123-132. doi:10.1111/j.1440-1797.2008.01073.x

17. Cass Chadban, SJ, Gallagher, MP, Howard, $\mathrm{K}$, Jones, A, McDonald, S, Snelling, PL,
White, SL A. The Economic Impact of EndStage Kidney Disease in Australia:

Projections to 2020. Melbourne, Australia: Kidney Health Australia; 2010.

18. Tucker PS, Kingsley MI, Morton RH, Scanlan AT, Dalbo VJ. The increasing financial impact of chronic kidney disease in australia. Int $\mathrm{J}$ Nephrol. 2014;2014:120537. doi:10.1155/2014/120537

19. Nakamoto H. Present status and future of peritoneal dialysis in Japan. Contrib Nephrol. 2015;185:116-123. doi:10.1159/000380975

20. Kao T-W, Chang Y-Y, Chen P-C, et al. Lifetime costs for peritoneal dialysis and hemodialysis in patients in Taiwan. Perit Dial Int. 2013;33(6):671-678. doi:10.3747/ pdi.2012.00081

21. Tantivess $S$, Werayingyong $P$, Chuengsaman $P$, Teerawattananon $Y$. Universal coverage of renal dialysis in Thailand: promise, progress, and prospects. BMJ. 2013;346(jan31 1):f462f462. doi:10.1136/bmj.f462

22. Pontoriero G, Pozzoni P, Vecchio L Del, Locatelli F. International Study of Health Care Organization and Financing for renal replacement therapy in Italy: an evolving reality. Int J Health Care Finance Econ. 2007;7(2-3):201-215. doi:10.1007/s10754-007 $-9016-9$

23. Luno J. The organization and financing of end -stage renal disease in Spain. Int J Health Care Finance Econ. 2007;7(4):253-267. doi:10.1007/s10754-007-9021-z

24. Australian Institute of Health and Welfare. Health Care Expenditure on Chronic Kidney Disease in Australia. Canbera: Australian Institute of Health and Welfare; 2009. https://www.aihw.gov.au/reports/healthwelfare-expenditure/health-careexpenditure-on-chronic-kidney-disease/ formats.

25. Kerr M, Bray B, Medcalf J, O’Donoghue DJ, Matthews B. Estimating the financial cost of chronic kidney disease to the NHS in England. Nephrol Dial Transplant. 2012;27(Suppl 3):iii73-iii80. doi:10.1093/ndt/gfs269

26. Zelmer JL. The economic burden of endstage renal disease in Canada. Kidney Int. 2007;72(9):1122-1129. doi:10.1038/ sj.ki.5002459

27. Durand-Zaleski I, Combe C, Lang P. International Study of Health Care 
Organization and Financing for end-stage renal disease in France. Int $J$ Health Care Finance Econ. 2007;7(2-3):171-183. doi:10.1007/s10754-007-9025-8

28. Benain J-P, Faller B, Briat C, et al. [Cost of dialysis in France]. Nephrol Ther. 2007;3

(3):96-106. doi:10.1016/

j.nephro.2007.03.001

29. Ashton T, Marshall MR. The organization and financing of dialysis and kidney transplantation services in New Zealand. Int $J$ Health Care Finance Econ. 2007;7(4):233252. doi:10.1007/s10754-007-9023-x

30. Tan C-C, Chan C-M, Ho C-K, Wong KS, Lee EJC, Woo KT. Health economics of renal replacement therapy: Perspectives from Singapore. Kidney Int. 2005;67:S19-S22. doi:https://doi.org/10.1111/j.15231755.2005.09405.x

31. Malaysia Society of Nephrology. 24th Report of the Malaysian Dialysis and Transplant Registry 2016. Kuala Lumpur; 2016.

32. Ismail H, Abdul Manaf MR, Abdul Gafor AH, Mohamad Zaher ZM, Nur Ibrahim Al. Economic Burden of End-Stage Renal Disease to the Malaysian Healthcare System. Kidney Int Reports. May 2019. doi:10.1016/ J.EKIR.2019.05.016

33. Hooi LS, Lim TO, Goh A, et al. Economic evaluation of centre haemodialysis and continuous ambulatory peritoneal dialysis in Ministry of Health hospitals, Malaysia. Nephrol. 2005;10(1):25-32. doi:10.1111/ j.1440-1797.2005.00360.x

34. Kumar Surendra N, Rizal Abdul Manaf M, Lai Seong $\mathrm{H}$, et al. The Cost Of Dialysis In Malaysia: Haemodialysis And Continuous Ambulatory Peritoneal Dialysis. Malaysian J Public Heal Med. 2018;18(2):70-81. https: / / www.mjphm.org.my/mjphm/journals/2018 Volume 18 (2)/THE COST OF DIALYSIS IN MALAYSIA HAEMODIALYSIS AND CONTINUOUS AMBULATORY PERITONEAL DIALYSIS.pdf. Accessed April 10, 2019.

35. Bavanandan S, Yap Y-C, Ahmad G, Wong H-S, Azmi S, Goh A. The Cost and Utility of Renal Transplantation in Malaysia. Transplant Direct. 2015;1(10):e45. doi:10.1097/ TXD.0000000000000553

36. Kleophas W, Reichel H. International study of health care organization and financing: development of renal replacement therapy in Germany. Int J Health Care Finance Econ. 2007;7(2-3):185-200. doi:10.1007/s10754-007 $-9020-0$

37. International Monetary fund. Consumer price index $(2010=100)$. The World Bank. https: / / data.worldbank.org/indicator/FP.CPI.TOTL. Published 2017. Accessed July 31, 2018.

38. World Bank. PPP conversion factor, GDP (LCU per international \$) | Data. World Bank . https: / / data.worldbank.org/indicator/ PA.NUS.PPP?locations=SG. Published 2018. Accessed July 23, 2018. 